Relato de Caso

CASE REPORT

\title{
Esclerite Associada ao Uso de Bisfosfonatos
}

\section{Scleritis Related to the Use of Bisphosphonates}

\author{
Ângelo Ferreira Passos ${ }^{(1)}$, Priscilla Jane Ayres de Almeida ${ }^{(2)}$
}

\section{RESUMO}

Alertar para o fato de que os bisfosfonatos, importante classe de drogas utilizada no tratamento da osteoporose, podem causar esclerite. Relatamos caso de uma paciente que apresentou episódio de esclerite durante o uso de alendronato e que recidivou com o uso de outra droga da mesma classe, o risedronato, um ano depois. Os bisfosfonatos constituem uma classe de drogas que tem sido, frequentemente, utilizada no tratamento da osteoporose. No entanto, boa parte da classe médica pode não estar alerta para os efeitos colaterais oculares, tendo em vista que não se encontrou relato desses efeitos na literatura nacional. Este trabalho mostra dois episódios de esclerite, ocorridos em uma mesma paciente, com intervalo de, aproximadamente, um ano, possivelmente, provocados pelo uso de dois tipos de bisfosfonatos. Nas duas ocasiões, houve resposta favorável à suspensão da droga, com a utilização de um tratamento pouco agressivo. Esse fato justificou a não realização da pesquisa de doenças consideradas causas de esclerite, das quais a paciente não apresentava sinais, sintomas, assim como qualquer história pregressa. Tudo isso, associado à existência, na literatura internacional, de relatos de casos de inflamação ocular, inclusive de esclerite, relacionados com o uso dos bisfosfonatos, reforça a hipótese de que os episódios, realmente, tenham sido provocados pelo uso da droga.

Palavras-Chave: esclerite, episclerite, bisfosfonato, inflamação ocular.

\section{INTRODUÇÃO}

Os bisfosfonatos são uma classe de drogas que atua inibindo a reabsorção óssea e vem sendo utilizada no tratamento de doenças ósseas, como doença de Paget, osteoporose, mieloma múltiplo, hipercalcemia em doenças malignas e metástase óssea osteolítica ${ }^{(1)}$.

Entre os bisfosfonatos disponíveis para uso, nos Estados Unidos, estão o pamidronato, o alendronato, o risedronato, o acido zoledrônico, o etidronato e o tiludronato ${ }^{(2)}$. Os bisfosfonatos mais utilizados são o etidronato, o alendronato, o pamidronato e o risedronato ${ }^{(3)}$.

\begin{abstract}
To alert to the fact that bisphosphonates, important class of drugs used in the treatment of osteoporosis, can cause scleritis. Report of a female patient's case, who presented an episode of scleritis while using alendronate, and who had one year later another episode during the use of a drug from the same class, risedronate. The bisphosphonates are a class of drugs, which have been used very often in the treatment of osteoporosis. However, a great part of the physicians can not be alert for its ocular side effects, considering that in the national literature there's no report of these effects. This article report two episodes of scleritis, occurred to a patient, in a period of one year, probably caused by the use of two types of bisphosphonates. In these two opportunities, there was recovery after the suspension of the drug, associated with a less aggressive treatment. This fact justified not to perform the search for diseases considered to be the cause of scleritis, of which the patient didn't show any sign, symptom or past clinical history. These facts, associated to the existence of some reports of ocular inflammation, including scleritis, associated to the use of bisphosphonates, reinforces the hypothesis that the episodes, in fact, have been caused by the use of the drug.
\end{abstract}

Keywords: scleritis, episcleritis, bisphosphonates, ocular inflammation.

Têm sido relatados efeitos colaterais sistêmicos com o uso dos bisfosfonatos, incluindo efeitos gastrintestinais (náuseas, vômitos, desconforto abdominal), renais (insuficiência renal), imunológicos (febre, mialgia, dor óssea ou articular), toxidermia e toxicidade ao sistema nervoso central $(\mathrm{SNC})^{(1)}$.

Efeitos colaterais oculares variados também têm sido relatados com os bisfosfonatos, sendo eles mais comuns com o pamidronato ${ }^{(2,4,5)}$.

Embora haja 19 relatos de esclerite com o uso de pamidronato $^{(2)}$, apenas quatro casos foram relacionados ao uso do alendronato $^{(2,6)}$ e apenas um com o risedronato ${ }^{(2)}$.

Serviço de Oftalmologia do Hospital Universitário Cassiano Antônio de Moraes (HUCAM), Universidade Federal do Espírito Santo (UFES). Recebido em 01/12/05. Aprovado, após revisão, em 07/07/06.

1. Chefe do Serviço de Oftalmologia do HUCAM da UFES, Professor Adjunto 4, Doutor em Oftalmologia pela Universidade Federal de Minas Gerais (UFMG), Pósdoutorado no Moorfields Eye Hospital, de Londres.

2. Residente (R3) do Serviço de Oftalmologia do HUCAM da UFES

Endereço para correspondência: Ângelo Ferreira Passos, Rua Ferreira Coelho, 304, Praia do Suá, CEP 29050-280, Vitória, ES, e-mail: angelopassos@terra.com.br 
O objetivo dessa publicação é relatar um caso de esclerite, ocorrido durante o uso do alendronato e que, mais tarde, recidivou com o uso do risedronato.

\section{RELATO DE CASO}

Paciente do sexo feminino, cor parda, 73 anos, em tratamento de osteoporose com alendronato, $70 \mathrm{mg}$, em dose única semanal, há mais ou menos 30 dias. Foi atendida em junho de 2002, com história de que, há poucos dias, havia apresentado quadro de vermelhidão, ardência e secreção no olho direito (OD). Usou colírio de tobramicina e, em seguida, outro colírio, com associação de ciprofloxacina e dexametasona, segundo ela, sem melhora do quadro. À biomicroscopia, apresentava hiperemia intensa e discreta quemose e a acuidade visual (AV) era de 20/20 em ambos os olhos.

Após 20 dias, apresentou piora do quadro, sendo atendida por um dos autores, com dor intensa no OD. Evidenciava-se, à biomicroscopia, hiperemia na porção superior do globo ocular, a cerca de $10 \mathrm{~mm}$ do limbo, com discreta elevação nodular subconjuntival, sendo o restante do exame normal e observando-se, como único fato digno de nota, a presença de pseudofacia (lente intra-ocular), bilateral. Tendo sido feito o diagnóstico de esclerite anterior, procedeu-se à suspensão da droga e à terapia com corticóide tópico (dexametasona $0,1 \%$ - quatro vezes/dia) e antiinflamatório não-esteróide (AINE) sistêmico (rofecoxibe). O primeiro foi utilizado por 30 dias, tendo sido feita sua retirada gradativa, e o segundo por 26 dias $(50 \mathrm{mg} / \mathrm{dia} / 13$ dias e $25 \mathrm{mg}$ /dia/13 dias). Com isso, observou-se melhora gradativa dos sintomas e remissão completa do quadro em aproximadamente 30 dias.

O único fato digno de nota, com relação à saúde da paciente, além da osteoporose, era de que, há mais ou menos 15 anos, era portadora de nódulo benigno da tireóide, e, embora com função tireoideana normal, fazia uso de Puran T4 (levotiroxina sódica).

Em novembro de 2003, a paciente retornou com história de que, há dois meses e meio, havia reiniciado o tratamento para osteoporose, desta feita com risedronato, $35 \mathrm{mg}$, em dose única semanal. Relatava que, desde pouco tempo após o início do tratamento, começou a apresentar ardência e leve hiperemia no OD. Queixava-se de dor ocular moderada e lacrimejamento e apresentava hiperemia bulbar superior, com discreta elevação subconjuntival, ao nível e pouco anteriormente à inserção do músculo reto superior direito, praticamente na mesma localização do episódio inflamatório anterior (Figuras 1A e 1B). O restante do exame era normal, inclusive a AV. Aventou-se, mais uma vez, a hipótese diagnóstica de esclerite, havendo melhora acentuada do quadro, após a suspensão do risedronato, com a administração de AINE sistêmico (rofecoxibe, 50 $\mathrm{mg} /$ dia). Esse medicamento foi utilizado por apenas cinco dias, passando-se a utilizar AINE tópico (cetorolaco de trometamina), com o que se manteve completamente assintomática, embora com persistência de discreta hiperemia por cerca de um mês.

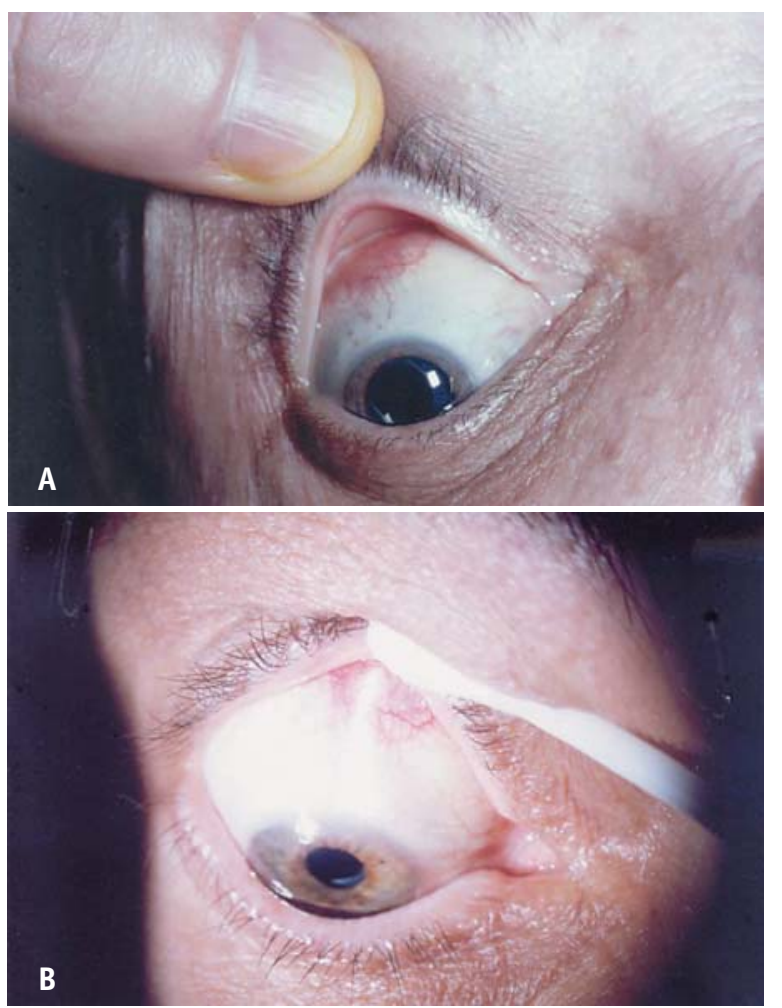

Figuras $1 \mathrm{~A}$ e $1 \mathrm{~B}$ - Segundo episódio de esclerite, este relacionado com uso de risedronato: A - iluminação difusa; B - corte óptico, mostrando lesão elevada.

Na ocasião do relato desse caso, 21 meses após a cura aparente do último episódio de esclerite, a paciente encontrava-se em tratamento da osteoporose, com outra classe de drogas, o cloridrato de raloxifeno, estando completamente assintomática, sob o ponto de vista oftalmológico.

\section{DISCUSSÃO}

Apesar de sua ampla utilização, os bisfosfonatos não estão isentos de importantes reações adversas em diferentes sistemas. Os efeitos colaterais oculares são variados, sendo que a maioria dos casos relatados está relacionada com o uso 
do pamidronato: 72 casos de conjuntivite inespecífica, 66 casos de uveíte anterior, 24 casos de visão borrada, 19 casos de esclerite, 16 casos de dor ocular, 14 casos de fotofobia, 10 casos de episclerite $^{(2)}$. Quanto ao alendronato, também são abundantes os relatos de complicações oculares: 94 casos de visão borrada, 33 casos de dor ocular, 30 casos de conjuntivite inespecífica, 19 casos de uveíte anterior e 4 casos de esclerite ${ }^{(2,6)}$. Com relação ao etidronato, foram relatados 18 casos de visão borrada e três casos de conjuntivite $^{(2)}$, enquanto que, com o risedronato, foram relatados sete casos de conjuntivite, dois casos de visão borrada, um caso de esclerite ${ }^{(2)}$ e um caso de episclerite ${ }^{(3)}$.

Portanto, embora o número de casos de esclerite relacionados ao pamidronato seja grande $(19 \text { casos })^{(2)}$, foram relatados apenas quatro casos de esclerite com o uso de alendronato $^{(2,6)}$ e um com o risedronato ${ }^{(2)}$. Quanto à episclerite, foram relatados 10 casos com o pamidronato $^{(2)}$ e apenas um caso com o uso do risedronato ${ }^{(3)}$. Nesse último caso, o quadro se iniciou sete dias após o início do uso do risedronato, regrediu com a suspensão da droga e a utilização de corticóide tópico e reapareceu após a reintrodução da droga (rechallenge).

As causas conhecidas de esclerite e episclerite incluem doenças inflamatórias sistêmicas, infecciosas, metabólicas e cutâneas. A paciente do caso em questão não apresentava sinal, sintoma ou história pregressa de qualquer uma das doenças, referidas como causa de esclerite ou episclerite. Com relação às doenças metabólicas, a esclerite tem sido relacionada à gota e a episclerite à gota e à tireotoxicose. No presente caso, a paciente apresentava função tireoideana normal, sendo apenas portadora de um nódulo benigno na tireóide, devido ao qual estava medicada com levotiroxina sódica.

Embora o teste da fenilefrina possa ser útil para a diferenciação entre os casos de episclerite e esclerite, muitas vezes o diagnóstico diferencial fica difícil. Os dois episódios desse caso foram diagnosticados como esclerite, levando-se em consideração, principalmente, a forte dor, relatada pela paciente no primeiro episódio, e de moderada intensidade no segundo, neste último, podendo haver alguma dúvida, quanto ao exato diagnóstico.

O tratamento da episclerite inclui o uso de esteróides tópicos e, nos casos mais prolongados, de AINEs sistêmicos, enquanto a esclerite anterior não necrosante, forma nodular ou difusa, é tratada com AINEs sistêmicos, esteróides sistêmicos (nos casos resistentes ou intolerantes aos AINEs) ou terapia combinada (AINE + esteróide). $\mathrm{Na}$ forma necrosante de esclerite, pode ser necessário o uso de imunossupressores (ciclofosfamida, azatioprina ou ciclosporina).

No caso em questão, nos dois episódios de esclerite, havendo a suspeita de que a inflamação ocular era devido ao bisfosfonato, da mesma forma que nos três casos relatados por Mbekeani et $a^{(6)}$, foi realizada a imediata suspensão da droga. Enquanto os citados autores complementaram o tratamento de dois dos seus casos com corticóide sistêmico e do outro com AINE sistêmico, no caso do presente trabalho, o tratamento foi complementado com o uso de AINE sistêmico e corticóide tópico (este, apenas quatro vezes/dia), no primeiro episódio, e apenas com AINE sistêmico, seguido de AINE tópico, no segundo episódio. O uso sistêmico dessa droga foi realizado não só pelo seu efeito antiinflamatório, mas, principalmente, para alívio da dor que a paciente apresentava, considerando que a medida terapêutica mais importante nesse caso, seria, a princípio, a suspensão imediata do bisfosfonato.

O objetivo da presente publicação é alertar a classe médica, principalmente, aqueles que prescrevem os bisfosfonatos e os oftalmologistas para essa causa de inflamação ocular, principalmente, levando em consideração que não se encontrou, na literatura nacional, nenhum trabalho publicado sobre complicações oculares dessa importante classe de drogas, amplamente utilizada no tratamento da osteoporose. Também nos livros textos não constam essas drogas como causa de esclerite ou episclerite.

O presente trabalho mostra dois episódios de esclerite, provavelmente, provocados pelo uso de dois tipos de bisfosfonatos. Nas duas ocasiões, houve resposta favorável à suspensão da droga, com a utilização de um tratamento pouco agressivo. Esse fato justificou a não realização da pesquisa de doenças, consideradas causas de esclerite, das quais a paciente não apresentava sinais, sintomas, assim como qualquer história pregressa. Tudo isso, associado à existência, na literatura estrangeira, de relatos de casos de inflamação ocular, inclusive de esclerite e episclerite, relacionados com o uso dos bisfosfonatos, corrobora a hipótese de que os episódios, realmente, tenham sido relacionados ao uso da droga.

Antes do envio do presente trabalho para publicação, um dos autores teve, em sua clínica privada, outros dois casos de esclerite anterior, em duas pacientes, fazendo uso de alendronato. Uma delas não apresentava qualquer patologia sistêmica que pudesse justificar o quadro ocular e a outra era portadora de polimialgia reumática, sob controle medicamentoso. Nos dois casos, procedeu-se à suspensão imediata do bisfosfonato. O primeiro caso foi 
tratado com sucesso, com a utilização de AINE sistêmico e corticóide tópico, com boa resposta, enquanto o segundo, que já fazia uso de metotrexato, teve boa resposta ao corticóide sistêmico.

Esses dois casos não foram incluídos na presente publicação, devido ao fato de que, principalmente, no segundo caso, em que a paciente era portadora de uma doença inflamatória sistêmica, só se poderia correlacionar, de maneira segura, a esclerite, com o uso do bisfosfonato, se viesse a ocorrer recidiva do quadro ocular, com a reintrodução da droga.

Declaramos a inexistência de conflitos de interesse.

\section{REFERÊNCIAS}

1. Adami S, Zamberlan N: Adverse Effects of Bisphosphonates - A comparative review. Drug Saf 14: 158-70, 1996.

2. Fraunfelder FW, Fraunfelder FT: Bisphosphonates and Ocular Inflammation. N Engl J Med 348: 1187-8, 2003.

3. Viñas G, Olivé A, Holgado S, Costa J: Epiescleritis secundaria a Risedronato. Med Clin (Barc) 118: 598-9, 2002.

4. Macarol V, Fraunfelder FT: Pamidronate disodium and possible ocular adverse drug reactions. Am J Ophthalmol 118: 220-4, 1994.

5. Fraunfelder FW, Fraunfelder FT, Jensvold B: Scleritis and other ocular side effects associated with pamidronate disodium. Am J Ophthalmol 135: 219-22, 2003.

6. Mbekeani JN, Slamovits TL, Schwartz BH, Sauer HL: Ocular inflammation associated with alendronate therapy. Arch Ophthalmol 117: 837-8, 1999. 